\title{
EDITORIAL s.opstan.
}

\section{LA PLURALIDAD DE LENGUAS: ¿BARRERA O ENRIQUECIMIENTO?}

En el Editorial del número 8(1) de Enseñanza de las Ciencias resaltábamos el carácter internacional que la revista ha ido adquiriendo a lo largo de sus ocho años. Con objeto de dar un nuevo impulso a esa cooperación internacional y proporcionar a los lectores una visión más amplia y enriquecedora de la investigación sobre didáctica de las ciencias,proponíamos la publicación de algunos artículos en su idioma original, acompañados de un amplio resumen en castellano. $Y$ aunque pensábamos que esa medida iba a recibir el apoyo mayoritario de los lectores y colaboradores de Enseñanza de las Ciencias, incluimos en los tres números del año 1990 un cuestionario destinado a implicar a los lectores y lectoras en la toma de decisión. Las respuestas obtenidas son mayoritariamente favorables (casi un 70\%) a la apertura idiomática propuesta. Consideramos, sin embargo, que el porcentaje de los que preferirían que se publicaran sólo trabajos traducidos es suficientemente elevado para obligar a una solución de compromiso, evitando que en un mismo número aparezcan más de uno o dos artículos no traducidos. Queremos insistir, pese a ello, en que esta medida no es sólo conveniente para agilizar la publicación de artículos (las traducciones suelen ser costosas y, en ocasiones, afectan a la calidad de los trabajos), sino que puede contribuir a deshacer el temor que existe a la lectura de un texto en catalán, italiano o portugués, mostrando que la pluralidad de lenguas en nuestro campo -por lo que se refiere al conjunto de idiomas latinos y al inglés como lengua internacional-constituye una barrera más fácil de superar de lo que puede imaginarse a priori. El esfuerzo -nunca excesivo- que ello exige queda ampliamente compensado por el enriquecimiento que supone el acceso directo a una producción escrita mayoritariamente en otras lenguas. 